\title{
SOBRE LUIGI FERRAJOLI Y EL CONSTITUCIONALISMO*
}

\author{
Francisco Laporta \\ Universidad Autónoma de Madrid
}

RESUMEN. El autor plantea una serie de objeciones al texto de Luigi FERRAJOLI. En primer lugar, se refiere a la construcción por parte de FERRAJol de una teoría que infiere de un modo exhaustivo, pero siempre deductivamente, el alcance de un complejo conjunto de términos primitivos y definiciones. En segundo lugar, el autor duda sobre la forma de ver y, sobre todo, de reconstruir el llamado «paradigma constitucional». En tercer lugar, el autor objeta el tratamiento que FERRAJOLI hace de los conceptos de «validez» y «vigor» de las normas. En cuarto lugar, hace referencia a la definición que FERRAJOL realiza del constitucionalismo garantista, en concreto a la consideración de éste como mejora o complemento del positivismo jurídico que se logra gracias a que el constitucionalismo observa no sólo el «ser» sino el «deber ser» del Derecho. Finalmente, repasa las críticas que FERRAJOLI realiza al constitucionalismo (la tesis de la separación entre Derecho y moral, la distinción entre principios y reglas y la crítica a la ponderación), expresando sus diferencias.

Palabras clave: FerRAJoli, constitucionalismo, validez y vigor, Derecho y moral, principios y reglas, ponderación.

ABSTRACT. In this paper, the author poses several general questions on Luigi FERRAJOL's paper. Firstly, he writes on FERRAJOLI's construction of a theory that comprehensively infers, still always in a deductive way, the scope of a complex set of primitive terms and definitions. Secondly, the author questions his way to understand and particularly to reconstruct the so-called "constitutional paradigm». Thirdly, the author writes about FERRAJOLI's approach to the concepts of «validity» and "enforcement» of rules. Fourthly, he discusses FERRAJOLI's definition of garantist constitutionalism, particularly his conception of this sort of constitutionalism as an improvement or complement to legal positivism -inasmuch as constitutionalism respects both the being of the Law and its normative or ideal (must be) dimension. Finally, he revises the objections that FERRAJOLI addressed to constitutionalism (the thesis of the separation between Law and morality, the distinction between principles and rules and the criticism of the weighting) introducing new arguments.

Keywords: FerRAJOLI, constitucionalism, garantismo, validity and force, morals and law, rules and principles, weighing.

* Fecha de recepción: 10 de enero de 2011. Fecha de aceptación: 7 de febrero de 2011.

Ángeles RóDENAS hizo valiosas precisiones y comentarios a este escrito. Me siento en deuda con ella por los errores y deslices que pude evitar con ello. La responsabilidad de lo que queda es, por supuesto, exclusivamente mía. 


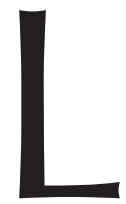

a obra de Luigi FERRAJOLI ha permanecido tan fiel a sí misma durante tantos años y ha sido objeto de tantos análisis y discusiones que parece imposible pretender ninguna originalidad al hacer comentarios sobre ella. No sé por ello si tiene mucho sentido volver hoy sobre objeciones que ya le han sido hechas y a las que, casi siempre rechazándolas, ya ha respondido. Por eso me inclinaré más bien por mostrar algunas dudas generales — tampoco, por lo demás, nuevas-que me han invadido a veces con su lectura, y comentar después, en términos más particulares, el texto que nos ofrece ahora sobre los dos tipos de constitucionalismo, el constitucionalismo llamado por él garantista y el constitucionalismo principialista. Helas aquí, un poco apresuradas y sumarias. Tómelas el lector (y el autor) más como perplejidades o dudas generales mías que como críticas minuciosas y elaboradas.

1. Hay una conocida propiedad de los sistemas deductivos que quisiera invocar para empezar. Como es sabido, sus conclusiones no amplían nuestro conocimiento del mundo; se limitan a mostrarnos explícitamente aquello que ya estaba implícito en sus axiomas y premisas. Es decir, que lo único que nos enseñan todos los corolarios y derivaciones que obtenemos de ellos, si somos rigurosos en las operaciones e inferencias, es el alcance exacto que tienen las proposiciones de las que hemos partido como estipulaciones primarias. Con su proverbial rigor, Luigi FERRAJOLI construye una teoría axiomatizada del Derecho de esta naturaleza, es decir, una teoría que infiere de modo exhaustivo, pero siempre deductivamente, el alcance de un complejo conjunto de términos primitivos y definiciones; pero, naturalmente, con ello no nos ha dicho nada del mundo, del mundo del Derecho en este caso, sino del potencial lógico-normativo que encierran en sí esos términos primitivos y definiciones interpretados exactamente como él lo hace mediante esa gran estipulación originaria. La teoría crea así una suerte de lenguaje normativo artificial en el que están todas las conclusiones posibles obtenidas a partir de las premisas y teoremas. Y que goza, cómo no, de las consabidas propiedades de consistencia y completud. De modo tal que a partir de él no puede hablarse de cosas tales como inmoralidad o injusticia de ese lenguaje normativo sino de mera inconsistencia o de mera incompletud (como es sabido, en la teoría de FERRAJOLI el Derecho «ilegítimo» lo es en virtud de una inconsistencia entre normas cuando es producto de una acción normativa, y en virtud de una incompletud cuando es producto de una omisión normativa). Y por lo que respecta a la validez de las conclusiones y corolarios, sólo puede hablarse de validez lógica, es decir, de la validez propia de un buen argumento que parte de premisas verdaderas y respeta las reglas de inferencia.

Naturalmente esto lo sabe perfectamente FERRAJOLI. Lo ha dicho desde siempre. Ya en 1983 escribía, efectivamente, que el lenguaje de la teoría del Derecho «es un lenguaje elaborado artificialmente, carente de referencia semántica directa con entidades observables, y por ello empleable en la formulación de conceptos y de asertos que, si bien resultan confirmables en la medida en que alcanzan a explicar y a sistematizar los resultados de la experiencia observadora, no están sin embargo conectados directamente con ella y se desarrollan deductivamente según una sintaxis explícita y rigurosamente preestablecida» ${ }^{1}$. Para añadir, algunos párrafos después, que «los conceptos de la teoría del Derecho se introducen a través de definiciones estipulativas o convenciones

1 L. Ferrajoli, «La semantica della teoria del diritto», en La teoria generale del diritto. Problemi e tendenze attuali. A cura de U. SCARPELl, Milano, Edizioni di Comunità, 1983, 105-106. 
establecidas por el teórico mismo y por él asumidas libremente en vistas a la finalidad explicativa perseguida por la teoría, así como son asumidos libremente los postulados que, unidos a las definiciones, representan las premisas a partir de las cuales, si la teoría está organizada de forma axiomatizada, se desarrollan deductivamente todas las demás tesis y teoremas de la teoría» ${ }^{2}$. En parecidos términos se sigue expresando todavía hoy en unos y otros escritos ${ }^{3}$.

Ahora bien, una propiedad que anima al lenguaje así construido es que el alcance tanto de los axiomas, como de los corolarios, deducciones y teoremas, así como el de las reglas de su gramática, está, en su poder significativo, libre de contexto alguno. Es una pura estipulación del teórico, como dice FERRAJOLI, y no puede estar sujeto a ninguna polisemia o ambigüedad que pudiera derivarse de un determinado contexto de uso, pues si lo estuviera su axiomatización sería lógicamente imposible. Su significado se fija de una vez por todas y no cabe reinterpretarlo o darle otro alcance semántico en función de los contextos posibles de emisión. Y sin embargo, FERRAJOLI afirma que tiene una base empírica y que cumple tareas pragmáticas en función de la interpretación que de él se dé. Este paso desde un sistema de significados cerrado sobre sí mismo a su aplicación a la realidad no acabo de verlo claro. Si tal lenguaje pretende cumplir funciones explicativas respecto del mundo, o, más aún, funciones críticas frente a él, ambas tendrán que ser siempre relativas a ese lenguaje, e imposibles, por tanto, de ser generalizadas como válidas fuera de él. Y por lo que respecta en particular a las funciones críticas, ha de estar siempre alerta ante el evidente riesgo de incorporar en los axiomas, definiciones y teoremas ciertos juicios de valor que después se presentan como pautas formales para hacer la crítica de la realidad normativa empírica, con lo que estaríamos en realidad ante un lenguaje ético o político suprapositivo (una suerte de Derecho natural) por mucho que se presentase con la asepsia de una axiomática neutral.

2. Otra duda que someto aquí a consideración se refiere a la forma de ver, y sobre todo de reconstruir, el llamado «paradigma constitucional». Dejando a un lado mi preferencia por teorías del Derecho de más alcance, creo sin embargo que la elaboración conceptual de la noción misma de «Constitución» que se efectúa a partir de las premisas normativas puede tener algún problema. La Constitución en ese nuevo «paradigma» se presenta con dos rasgos básicos: en primer lugar, se sitúa en el vértice del ordenamiento jurídico; en segundo lugar, está dotada de rigidez, en el sentido de que es inaccesible a las competencias cotidianas del legislador. No se menciona, aunque parece pretenderse que se deduce de ello, que la constitución tiene un fuerte carácter vinculante, que es normativa, obligatoria, o como quiera que eso se exprese ${ }^{4}$. Ahora bien, para presentar la génesis de su concepto se recurre a una secuencia conceptual como la siguiente: se parte de un término primitivo («constituyente») que designa situaciones no producidas por ninguna causa, actos ejercidos en tales situaciones y sujetos que se encuentran en ellas y producen esos actos ${ }^{5}$. Con ese término primitivo —se

2 Ibid., 109.

3 Por ejemplo en L. Ferrajoli, J. J. Moreso y M. Atienza, La teoría del Derecho en el paradigma constitucional, Madrid, Fundación Coloquio Jurídico Europeo, 2008, 27 y ss., o, en fin, en Principia Iuris. Teoría del diritto e della democracia, Editori Laterza, 2007, I, 19.

${ }^{4}$ En el trabajo que discutimos aquí sobre el constitucionalismo garantista esa fuerza vinculante, esa normatividad de la Constitución juega obviamente un papel decisivo.

5 En Principia Iuris, cit., 89. 
afirma - se pretenden evitar nociones como la de «soberanía» o la de «norma hipotética fundamental». Pero la particularidad originaria y fundadora que denota ese término se manifiesta sobre todo en que es siempre ajeno a todo tipo de «regulación», no tiene, pues, ninguna denotación ni alcance normativo. Ni la situación constituyente, ni el sujeto constituyente, ni el acto constituyente ni el poder constituyente están sometidos a reglas (100). Se trata de una situación de facto que es habitada por un sujeto «natural» (no artificial) (299, nota 36), que no realiza actos normados sino actos «brutos», naturales, en virtud de facultades que no están previstas en normas sino que son un puro poder hacer de hecho, el poder constituyente $(328)^{6}$. Es ese poder el que genera la Constitución.

Pues bien, hay aquí al menos dos incógnitas para mí. La primera de ellas es que en algún lugar de la cadena que va desde una pura situación fáctica a una constitución normativa ha de haberse producido un salto lógico cuestionable. Para FerRAJOLI la Constitución es algo con un alcance normativo muy acentuado. Esto quiere decir que allí donde la Constitución dice que algo «debe ser hecho», ese algo debe ser hecho. Tiene pues una vinculatoriedad evidente. Pues bien, no entiendo muy bien de dónde puede obtener esa vinculatoriedad si es el precipitado de una secuencia de acciones humanas que se producen en el puro mundo de los hechos.

La segunda incógnita proviene para mí del empleo, por otra parte muy aceptado, de la idea misma de poder constituyente originario. En la literatura al uso, y también en nuestro autor, esa actividad que se postula como existente y real -acciones de hombres y mujeres de «carne y hueso», dice FERRAJOLI-, no puede identificarse sino cuando la Constitución ha sido ya puesta en pie. Se trata por tanto de una realidad cuya detección sólo puede realizarse ex post. Sabemos que ha existido porque hay una Constitución. Y la pregunta que he hecho siempre ante este género de argumentación «teológica» es si no será superfluo todo ese aparato conceptual previo a la Constitución cuando ya tenemos la Constitución misma como conjunto de normas válidas. Siempre me ha parecido una suerte de innecesaria explicación de carácter mágico apelar a un sujeto originario, misterioso y omnipotente que no acaba por ser sino una antropomorfización ad hoc de procesos sociales complejos que incluyen ya, como no podía ser de otra manera, dimensiones normativas. El problema con el que siempre se encuentran los positivistas es el de dar cuenta de la supuesta normatividad inherente al Derecho. Y cuando se trata de subrayar con tanta fuerza la vinculatoriedad de la Constitución, el problema de la normatividad de la Constitución. Esa es la cuestión que trataba de resolver KELSEN con su norma hipotética fundamental, que, recuérdese, en una de sus formulaciones decía: «Se debe obedecer la Constitución». Y es una cuestión que no está nada claro que pueda resolver FERRAJOLI aportando datos sobre situaciones de hecho, sujetos naturales y capacidades fácticas de actuar. El constitucionalismo rígido o garantista necesita algo más que eso.

3. Otra de las dudas generales que me ha suscitado siempre el pensamiento jurídico de FERRAJOLI se refiere a una de esas grandes «divaricazioni» que se subrayan en su teoría del Derecho. A la más importante de ellas, creo: la que se da entre «validez» $\mathrm{y}$ «vigor» de las normas. Aquí ni siquiera es necesario citar minuciosamente porque es

\footnotetext{
${ }^{6}$ La secuencia casi completa puede encontrarse en 849-850.
} 
uno de esos temas tan recurrentes en su obra que apenas puede encontrarse trabajo suyo en que no aparezca. Y respecto a esa divergencia se le ha preguntado a veces a FERRAJOLI, en primer lugar, si no se daba también en el llamado Estado legislativo de Derecho, Estado legal o Estado de Derecho en sentido débil. También en él las leyes tienen contenidos formales o procedimentales y contenidos materiales, y con frecuencia habilitan a órganos subordinados al legislador para crear normas que deben respetar el contenido material de las normas legales. Y puede darse el caso, se da de hecho con frecuencia el caso, de que en el ejercicio legítimo de sus competencias tales órganos creen normas jurídicas que violan el contenido material de leyes a ellas supraordinadas. La prueba de ello es que, tanto en España como en otros países cercanos, existe un procedimiento judicial para remediarlo: el recurso contencioso-administrativo contra disposiciones de carácter general destinado desde hace muchos años a corregir esas extralimitaciones. Ley y reglamento han estado pues sometidos a la misma disciplina que se expresa en la divergencia «validez»/«vigor». Lo que ha hecho el Estado constitucional de Derecho ha sido simplemente ampliar esa misma disciplina a las relaciones entre la Constitución y el legislador. Y poner bajo una jurisdicción especial — pero esto no en todos los casos ni con el mismo alcance- esas eventuales «antinomias» y «lagunas» que producía el legislador al contravenir o ignorar la Constitución.

Pero la cuestión mayor para mí no es esa, que, como digo, se le ha formulado ya algunas veces a FERRAJOLI. La cuestión más difícil es la que proviene de esta reflexión: ¿no será, al fin y al cabo, esa divergencia una manera sólo parcial de poner de manifiesto, y una manera un tanto ingenua de ofrecer una solución para, un problema fundamental e inevitable que habita siempre en el orden jurídico? Trataré de explicarme. El Derecho parece tener dos almas diferentes: un alma material y un alma procedimental. La primera se expresa en normas de conducta, principios, exigencias de comportamiento, contenidos materiales de derechos y deberes, etc. La segunda se expresa en el establecimiento de órganos y procedimientos para tomar las decisiones necesarias sobre el contenido y el alcance de las normas de la primera, las soluciones para poner fin a conflictos o resolver desacuerdos respecto a ellas, etc. Y resulta que ambas «almas» pueden acabar en soluciones jurídicas o decisiones finales que entren en conflicto las unas con las otras. Bruno CELANO y José Juan MORESO han mostrado con gran agudeza esta naturaleza inherentemente conflictiva que puede tener el orden jurídico contemporáneo, lo que yo he llamado sus dos «almas». Hay en todo orden jurídico normas que establecen deberes y derechos, y como se da el caso de que algún órgano de decisión, en algún momento, y según algún procedimiento formalizado, tiene que decir la última palabra sobre el alcance de esos derechos y obligaciones y sus posibles conflictos, entonces puede resultar que esa decisión última no encaje con el tenor literal de las normas materiales sobre ese alcance y esos conflictos. Eso es lo que, por ejemplo, recordaba HART, cuando distinguía entre decisión última y decisión infalible. FERRAJOLI presenta como nueva y propia del «paradigma» constitucional, la visión de que eso se produce entre normas de diferente rango, especialmente entre normas constitucionales y normas con rango de ley, o entre poderes constituyentes y poderes legislativos, y abraza la solución adoptada por los sistemas constitucionales de posguerra de someter esos conflictos a una jurisdicción especializada. Pero quizás el problema es mucho más general y más hondo, quizás es de hecho un problema estructural del orden jurídico, la posible contradicción entre soluciones halladas a través 
de la red de procedimientos, competencias, etc., que todo orden jurídico tiene que establecer y la que ofrecen las normas de conducta que emite. Y se produce siempre, en niveles normativos jerárquicamente diferentes y en niveles normativos del mismo rango. ¿Acaso no es posible pensar en un juez constitucional que tenga la competencia de decir la última palabra y con esa última palabra ignore normas materiales de la Constitución? Esto, si lo he entendido bien, es lo que José Juan MORESO ha llamado recientemente «caso Julia Roberts»: la posibilidad de que el superior órgano decisor en cuestiones constitucionales, lisa y llanamente se equivoque, $\mathrm{o}$, peor, ignore deliberadamente la Constitución ¿No es posible imaginar un auténtico poder constituyente (un poder constituyente constituido) que cree normas constitucionales antinómicas respecto de otras normas constitucionales en vigor? Suponer que en esos casos, para resolver la antinomia, podemos volver a criterios automáticos como el «cronológico» o de «especialidad» parece un simplismo excesivo. De hecho se dan muchos casos en los que sobreviven como válidas o en vigor normas en conflicto, lo que, como es de todos conocidos, plantea serios problemas teóricos. Y luego, claro, está el problema, que ya preocupó a KELSEN (al KELSEN anterior al constitucionalismo de posguerra, por cierto $)^{7}$, del tipo de alcance que habría de tener la decisión de expulsar la norma inconstitucional del ordenamiento; si había de ser declarada nula ex nunc, como mantenía KeLSEN, o ex tunc, como sería seguramente lógico, con los problemas que ello comporta, como el del estatus que haya podido tener su extraña vigencia en un caso o en el otro.

4. Y vamos ya con el texto que se trataba de discutir ahora. En él, tras una propuesta de renovación terminológica, aparece una presentación muy sumaria del llamado constitucionalismo principialista que me parece un tanto sesgada, pero que en todo caso ya se encargarán los autores en ella aludidos de defender. Paso, pues, directamente, al epígrafe 3, en el que se hace una correlativa presentación (también breve: cinco páginas) del otro constitucionalismo, el garantista, algunos de cuyos extremos vale la pena comentar. En ella se afirma que este constitucionalismo es un positivismo reforzado y ofrece además un vínculo o nexo entre positivismo jurídico y democracia. Pues bien, ninguna de estas dos afirmaciones me parecen convincentes.

La manera de expresar el cambio del «paradigma» respecto del llamado viejo positivismo es afirmar que en el constitucionalismo garantista se somete la producción normativa a normas no sólo formales sino también materiales del Derecho positivo. Esta mejora o complemento del positivismo jurídico se logra porque el constitucionalismo, se dice, «positiviza» no sólo el «ser», sino también el «deber ser» del Derecho. El Derecho ahora ve reguladas no sólo las «formas» («como en el viejo paradigma formalista del paleo-positivismo»), sino también los «contenidos», mediante los límites y vínculos que le impone el paradigma constitucional. No veo nada claro qué sea eso de «positivizar el deber ser», ni por qué no lo hacía también el Derecho del que daba cuenta el «paleopositivismo». Tampoco, por cierto, me parece claro qué designa esto de paleopositivismo. ¿Incluye a Austin, por ejemplo, o a Bоввіо?

7 Para una exposición de ello, cfr. S. PAULSON, «What counts as "constitutional”?», en Rechtstheorie, Beiheft 13, Politische Herrschaftsstrukturen und Neuer Konstitutionalismus - Iberoamerika und Europa in theorievergleichender Perspektive. 
A no ser que sea una simple façon de parler un tanto imprecisa, a mí me parece que el Derecho positivo siempre ha positivizado el deber ser. O, por decirlo con más rigor, que las normas del Derecho positivo han tenido siempre como contenido conductas que debían ser realizadas, y también, como he recordado antes, procedimientos y competencias. Esto me parece tan evidente que no llego a entender qué significa el correlativo positivizar el «ser del Derecho», que, al parecer, es lo único que hacía el paleopositivismo. Parece según el texto que el orden jurídico en que piensa el viejo positivismo sólo se dedicaba a crear el órgano legislador, mientras que el orden jurídico del nuevo positivismo reforzado le impone también contenidos a su labor. Pero a mí me parece que las cosas no son tan oscuras. Sucede sólo que la intensificación de la fuerza normativa de la Constitución ha hecho más complejo el ordenamiento, incorporando por encima de la ley un escalón superior con normas de conducta y normas de competencia; igual que el regionalismo o federalismo lo ha hecho también más complejo incorporando en los niveles legales normas de conducta y normas de competencias exclusivas de los órganos legislativos de las regiones, autonomías o länder. El positivismo jurídico puede dar cuenta de esto sin grandes alteraciones, a condición claro está de que se provea de una buena teoría de la Constitución. Esto es algo que, como he dicho, yo no encuentro en FERRAJOLI, que confía muchas cosas — quizás demasiadas- a la aparición de las Constituciones de posguerra y no tiene una teoría de la Constitución que dé cuenta de ellas y su valor vinculante. En esto su teoría me parece que se sitúa más cerca de la mentalidad del dogmático del Derecho constitucional que de la actitud del teórico del Derecho. Los constitucionalistas, al menos los españoles, toman la Constitución exactamente igual que el registrador toma la Ley Hipotecaria: esto es lo que vale como norma y hay que interpretarlo y aplicarlo. Pero a la teoría del Derecho se le debe exigir algo más que eso (en mi opinión, también al Derecho constitucional, pero eso es harina de otro costal).

Por lo que respecta al presunto nexo que FERRAJOLI afirma que el paradigma constitucional establece entre el positivismo jurídico (supongo que el reforzado, no el «paleo») y la democracia, tampoco las cosas me parecen muy claras. En primer lugar, no encuentro ninguna razón para que una teoría del Derecho, como es el positivismo jurídico, se pronuncie o no se pronuncie por la democracia. Si se trata de una teoría descriptiva y neutra que busca una base empírica en los Derechos positivos, entonces todo dependerá del contenido de esos Derechos positivos. Aquí FERRAJOLI vuelve sobre eso de la positivación del «deber ser», pero eso será en todo caso algo que hagan (o no hagan) las constituciones, no las concepciones del Derecho. Se afirma en el texto que el nexo entre democracia y positivismo ha sido comúnmente ignorado, y se propone que debemos «reconocer que sólo la rígida disciplina positiva de la producción jurídica está en condiciones (in grado) de democratizar tanto las formas como los contenidos». Seguramente sí, pero eso lo hará — si es que lo hace- la aplicación de las normas constitucionales correspondientes, y no el positivismo jurídico. De forma que ese presunto nexo puede seguir siendo ignorado sin que suceda nada importante ni en la teoría ni en la democracia.

Y luego, además, resulta un poco sorprendente que se afirme que el paradigma constitucional es el que ha dado a luz una teoría de la democracia. Dejando a un lado que la teoría de la democracia es bastante más vieja que dicho paradigma, el asunto, naturalmente, dependería de lo que entendiéramos por democracia. Y a este respec- 
to no debemos olvidar que hay una extensa literatura que parece apuntar a que una constitución rígida y supraordinada a las mayorías electivas es una severa limitación del ideal democrático, si es que ese ideal tiene algo que ver con el principio de la mayoría y de elección de los representantes. No es éste, sin embargo, un tema que podamos discutir aquí, pero vale la pena recordar también esa posible contingencia de que las constituciones no alumbren sino que limiten el principio democrático.

5. El grueso del escrito de FERRAJOLI (16-44 del original italiano) es una crítica minuciosa de las tres tesis más importantes del constitucionalismo llamado principialista o no positivista. Si acabo de hacer unas breves y apresuradas críticas al constitucionalismo que propone FERRAJOLI, ello se ha debido a que el lector del texto puede tener la impresión de que si las críticas que él hace a aquel tipo de constitucionalismo principialista tienen éxito, su derrota supondría de algún modo un reforzamiento del otro constitucionalismo. En FERRAJOLI no cabe suponer un argumento tan falaz, pero la estructura del texto invita al lector a pensar que los ataques al principialismo no positivista resultan ser una victoria para el constitucionalismo positivista. Y puede ser sin embargo que FERRAJOLI tenga razón (al menos en parte) en las críticas que hace al otro tipo de constitucionalismo, y ello sin embargo no suponga ningún beneficio para el constitucionalismo que él mismo propugna. Ése, sin ir más lejos, es mi punto de vista.

FERRAJOLI se opone en el texto a tres tesis básicas del neo-constitucionalismo principialista: la tesis de la conexión necesaria entre Derecho y moral, la tesis fuerte de los principios y la tesis de la ponderación en los conflictos entre principios. Yo tampoco acepto así como así esas tres tesis, y en esto concuerdo con FERRAJOLI, pero no lo hago por las mismas razones que él. Mi voto es, si así pudiera decirse, de los llamados «concurrentes» con el fallo de FERRAJOLI, pero mis argumentos difieren de los que él esgrime. Iré presentándolos por orden.

A) La tesis de la separación entre Derecho y moral es combatida por los neoconstitucionalistas tomando como base la evidente presencia de principios de justicia y valores éticos en la textura misma de los textos constitucionales. FERRAJOLI por su parte afirma en contra de ellos que, a pesar de la evidencia de que las normas jurídicas incorporan aspiraciones de carácter moral, la conexión entre Derecho y moral no se da, y no se da precisamente porque la constitución ha positivizado esos principios transformándolos en normas jurídicas, y no en exigencias morales. «Es, por tanto, insostenible la derivación, a partir de la circunstancia obvia de que las leyes y las constituciones "incorporan" valores, de la tesis de una "conexión" conceptual entre Derecho y moral», escribe. En esto estoy de acuerdo con él, aunque, como digo, por otras razones. Pero a continuación FERRAJOLI se adhiere a una posición metaética con la que es ya mucho más difícil concordar. Vayamos por partes.

a) La posición de ambos bandos en la cuestión de si los principios de justicia acogidos en las Constituciones comportan o no comportan una conexión necesaria entre Derecho y moral está, a mi juicio, mal orientada. Es obvio que la presencia de algunos principios obliga al intérprete a desarrollar argumentaciones morales, aunque sólo sea en la determinación de su significado y alcance, pero también es obvio que el intérprete no lo hace por un capricho ético-político personal, sino porque los encuentra recogidos en la Constitución como normas jurídicas positivas. Lo que sucede es que, a mi 
juicio, la tesis de la separación conceptual entre Derecho y moral no se dirime ahí, en el terreno de los principios y las normas de conducta, sino en el campo de la ineludible naturaleza procedimental del orden jurídico de la que antes hemos hablado. Veámoslo con un ejemplo: supongamos que ATIENZA, FERRAJOli, RUIZ MANERO y yo somos convocados por un club de estudiantes para encontrar una respuesta a la cuestión sobre la constitucionalidad de la nueva fórmula de reconocimiento del matrimonio entre personas del mismo sexo en el orden jurídico español. Con toda modestia por mi parte, estoy seguro de que en un breve espacio de tiempo llegaríamos a una solución compartida y seria sobre el tema. Pero al mismo tiempo, el Tribunal Constitucional español está deliberando sobre el mismo problema y llega a otra solución, seguramente ni tan seria ni tan compartida. Todo el mundo estaría de acuerdo en que la única de esas dos soluciones que es un fallo jurídico, es decir, un fallo que se incorpora al orden jurídico español, es la del Tribunal Constitucional. ¿Por qué? ¿Es porque ha desarrollado una sesuda argumentación moral como la que demandan ATIENZA y Ruiz MANERO? No. $¿ E s$ porque ha delimitado con claridad y desde dentro del ordenamiento una norma constitucional, al estilo de FERRAJOLI? Tampoco. Esas dos cosas las hemos podido hacer nosotros cuatro mucho mejor. Es simplemente porque de acuerdo con las normas procedimentales de competencia del orden jurídico español, el único órgano cuyas decisiones son normas jurídicas en ese ámbito es el Tribunal. Y en ese sentido su fallo es norma jurídica cualquiera que sea su relación con normas o principios morales, es decir, es Derecho (en España) tenga o no tenga relación con la moral. O lo que es lo mismo, es Derecho sin tener relación necesaria o lógica con la moral. Esta tesis de la separación, entendida así en términos de procedimientos y competencias, en términos de pedigree, como afirmaría HART, se me antoja una importante conquista del positivismo jurídico entendido como teoría del Derecho, y no creo ni que se haya tambaleado por la existencia de principios ni que se haya reforzado por la positivización de tales principios en la Constitución.

b) Pero después, como he dicho, FerRAJOLI entra en el campo de la metaética y expone, en un razonamiento que pretende encadenado, que las posiciones de ALEXY, ATIENZA y MORESO defienden un objetivismo ético, que tal objetivismo ético implica una opción en favor del cognoscitivismo ético, que esta posición acaba inevitablemente en el absolutismo moral, y tras él en el despeñadero de la intolerancia para con las opiniones morales disidentes. Algunos párrafos después afirma que, por el contrario, el no-cognoscitivismo y la separación entre Derecho y moral son garantía del pluralismo moral y del multiculturalismo, es decir, de la convivencia pacífica de las muchas culturas que conviven en una sociedad, y además, son la mejor garantía del sometimiento del juez a la ley y de su independencia. Esta cadena de razonamientos me resulta sorprendente; de hecho creo que todos ellos son profundamente controvertibles. No voy a poder argumentarlo ahora, pero no dejaré por ello de hacer algunas afirmaciones sumarias. Que el objetivismo ético implique el cognoscitivismo o cognitivismo ético es muy dudoso. El objetivismo ético sólo afirma que las normas morales están por encima de nuestras preferencias o intereses subjetivos, o que no puede darse cuenta de ellas sólo en función de éstos; y el cognoscitivismo por su parte que los enunciados morales son susceptibles de verdad o falsedad. Ambas cosas no tienen por qué estar implicadas; y que ambas cosas lleven al abolutismo moral, es decir, al dogmatismo en materias morales, es aún más discutible, y que conduzcan después a la intolerancia es directamente 
un non sequitur, bastante conocido, por cierto. Igual que lo es el suponer que el subjetivista, no-cognitivista, relativista moral, etc., será sólo por ello un ser tolerante.

Es evidente que todos estos desacuerdos merecerían un examen mucho más pormenorizado, imposible de hacer ahora. Sólo quiero, para cerrar este epígrafe, mencionar algo que FERRAJOLI afirma como una suerte de obiter dictum sorprendente. Está incluido en los argumentos que acabo de mencionar: que el no-cognoscitivismo y la separación entre Derecho y moral son garantía de... ¡la independencia judicial! Por más que me esfuerzo no consigo ver por qué el objetivismo y el cognoscitivismo pueden ser una amenaza a la independencia de los jueces, y las posiciones escépticas respecto de la ética pueden ser garantía de independencia de los jueces. Esto es algo que, sin duda, exige alguna aclaración.

B) El segundo objetivo crítico de FERRAJOLI es la tesis de la distinción entre principios y reglas. En este tema también puedo registrar acuerdos con el texto. Me inclino también por debilitar la distinción o, mejor dicho, su alcance. Digamos que me encuentro entre los que mantienen que se trata de una distinción débil, de grado, no de una distinción fuerte, de naturaleza lógica u ontológica. Sin embargo, quizás no los veo de la misma forma que él, y sobre todo, no veo en ellos esos desastres que él augura.

Dentro de una actitud de desconfianza hacia la distinción, FERRAJOLI acepta que pueda diferenciarse entre lo que llama principios directivos o directivas, y los que llama principios regulativos. Esta distinción le parece análoga a la formulada por ATIENZA y RUIZ MANERO entre directrices y principios en sentido estricto. Los primeros son los que «enuncian valores o directivas de carácter político, de las que no es exactamente identificable la observancia o la inobservancia». Pero afirma que se trata de normas «relativamente marginales». De ellos acepta que puedan ser, como lo propone AlEXY, «mandatos de optimización» que se caracterizan por poder ser satisfechos en grados diversos y están privados de supuestos de hecho que puedan configurar su inobservancia. Hasta aquí pues, no hay grandes desacuerdos entre ellos.

Donde empiezan esos desacuerdos es en esta afirmación: «Todos los demás principios [...] son en cambio regulativos, siendo materialmente posible pero deónticamente prohibida su inobservancia», escribe FERRAJOLI ${ }^{8}$. Y mantiene que lo que se da es simplemente una diferente manera de formularlos. Lo que parecen principios son en realidad reglas formuladas con referencia a su «respeto» en lugar de formuladas con referencia a su «violación y su consiguiente aplicación». Por eso afirma que la diferencia es poco menos que de estilo. Las reglas son opacas, en el sentido conocido de que, a pesar de que existe tras ellas un principio subyacente, tal principio no es mencionado, mientras que la formulación del principio expresa claramente la exigencia de respeto a esos valores que subyacen a las reglas. «Pero dejando a un lado el estilo - escribecualquier principio que enuncia un derecho fundamental, por la implicación recíproca que liga las expectativas en las que consisten los derechos con las obligaciones y prohibiciones correlativas, equivale a la regla que consiste en la obligación o prohibición

${ }^{8}$ En nota 54, afirma, por tanto: «La diferencia cualitativa o estructural no es, por tanto, entre reglas y principios, sino solamente entre principios regulativos y lo que he llamado "principios directivos", que consisten en expectativas, no de actos determinados sino de resultados, es decir, de políticas idóneas para realizarlos mediante una pluralidad de actos indeterminados y no predeterminables normativamente». Esto es lo que juzga él una distinción análoga a la de ATIENZA y RUIZ MANERO, entre principios en sentido estricto y directrices. 
correspondiente». Y, generalizando: «Se comprende así cómo no existe una diferencia real de estatus entre la mayor parte de los principios y las reglas: la violación de un principio hace de éste una regla que enuncia las prohibiciones y obligaciones correspondientes».

Lo que resulta para mí poco convincente en esta reconstrucción (de la que, insisto, no me encuentro demasiado lejano) es la aparente facilidad con la que FERRAJOLI pretende conocer las obligaciones y prohibiciones «correlativas» al enunciado de la regla-principio (por así llamarla). Por ejemplo, la afirmación de la dignidad humana le parece a él una regla-principio, y el deber de no realizar conductas contrarias a esa dignidad, le parece la correlativa «regla-regla». Pero claro, el problema que plantean los principios es precisamente éste, el de saber cuándo nos encontramos en el campo de aplicación de esa formulación tan vaga y tan abstracta (principio de dignidad humana, principio de no discriminación, etc.), es decir, cuándo nos encontramos ante una conducta contraria a la dignidad humana. $\mathrm{Y}$ es seguramente la magnitud y los borrosos límites que tiene ese campo de aplicación lo que suscita realmente los problemas. Unos problemas que no se resuelven simplemente con la afirmación de que en realidad son reglas que prohíben cosas, sino estableciendo los argumentos necesarios para saber qué cosas prohíben dada su pasmosa indeterminación. Es, seguramente, a esta circunstancia inevitable a la que se debe la elaborada construcción actual a partir de DwORKIN de la teoría de los principios.

No voy a entrar ahora en ella. Prefiero, en aras de la discusión, poner precisamente en tela de juicio que la construcción de FERRAJOLI evite los males que atribuye a la idea de principios: la despotenciación de su valor vinculante, y el desarrollo de lo que él llama, con expresión muy feliz, «inventiva jurisprudencial». Respecto del primero de esos males, hay que decir que nuestro autor mezcla en sus críticas aspectos diferentes de la teoría de los principios, incluso tipos diferentes de principios. Una cosa es la llamada «derrotabilidad» de las normas constitucionales (GARCía FigueroA) y otra diferente es la teoría del mandato de optimización (ALEXY) o del carácter «programático» de las directrices (ATIENZA y RUIZ MANERO). La primera de ellas puede ser vista como la formulación de un problema real: cuando descendemos a los particulares de un caso puede ser que las soluciones que sugieran las formulaciones abstractas y vagas de dos normas constitucionales entren en conflicto, en cuyo caso una de ellas resultará no aplicable. Lo que llamo sugerir es, más o menos, lo que en esa literatura se llama ser debido prima facie; lo que llamo no aplicar, es lo que se llama allí, ser derrotado. Pero al margen de la terminología más o menos satisfactoria, no me parece que lo que se trata de enfrentar en esa teoría no sea un problema real, y sobre todo, no me parece que la solución de FERRAJOLI logre resolverlo sencillamente. Decir que las normas constitucionales son obligatorias, o que tienen «portata normativa», no hace más fácil identificar qué conductas permiten o prohíben, y, desde luego, no hace desaparecer los conflictos entre las soluciones posibles. Otra cosa distinta es el carácter «programático» de las directivas o lo que ALEXY llama «mandato de optimización». Hay normas constitucionales que establecen, como ha reconocido poco antes el propio FERRAJOLI, objetivos y resultados, que configuran, por así decirlo, un plan o programa de acción y cuyo destinatario seguramente no es el ciudadano, sino los poderes públicos competentes para realizar una acción política. Aquí puede haber un deber genérico de encaminarse en una dirección, pero no una panoplia de conductas estrictamente 
obligatorias para el legislador o el Gobierno. Y a eso me parece que se refieren ellos cuando dicen que tienen una naturaleza programática, y no, como se presume que sucedía en el constitucionalismo del siglo XIX o en las proclamas legales de los regímenes fascistas, a que los principios y normas constitucionales son meros píos deseos que no obligan al legislador.

Y vamos ahora a la «inventiva jurisprudencial», de la que hay múltiples ejemplos, pero, mucho me temo, tanto entre jueces «principialistas» como entre jueces «garantistas». Escribe FERRAJOLI: «Pero hay otro aspecto, todavía más perverso y engañoso del enfoque antipositivista y principialista a las constituciones. La idea de que las normas constitucionales no son normas rígidamente vinculantes a las que están sometidas la jurisdicción y la legislación porque se hallan jerárquicamente subordinadas a ellas, sino principios ético-políticos fruto de argumentaciones morales, ha favorecido, allí donde desafortunadamente no ha permanecido confinada en el debate académico entre filósofos del Derecho, el desarrollo de una inventiva jurisprudencial que se ha manifestado en la creación de principios que no tienen ningún fundamento en la letra de la Constitución». FERRAJOLI afirma que la sustancia del garantismo es precisamente que el juez (y, por supuesto, también el legislador) se hallan sometidos a los principios constitucionales como normas prescriptivas no neutralizables por principios ético-políticos, sean de creación legislativa sean de creación judicial. Pero el efecto perverso puede producirse también al revés, porque si las cláusulas constitucionales son imprecisas, vagas o indeterminadas (como lo son tantas veces), la inventiva del garantista puede consistir en incluir en su campo de aplicación supuestos inventados o preferencias personales para afirmar solemnemente después que eso y sólo eso es lo que la letra de la constitución dicta. El principialista se abandonaría a la argumentación moral con toda claridad, pero el garantista, que se ve constreñido a hacer algo muy similar, tendría además la posibilidad de disfrazar este hecho inevitable con una apelación solemne al dictado de las normas. Dada la formación que tienen los jueces, y la que seguimos dando en nuestras Facultades, un juez principialista es, sin duda, un peligro público, pero al menos adopta una posición honesta porque anuncia que ha desarrollado un argumento moral y abre así un debate posible; un juez garantista, por el contrario, haría exactamente lo mismo pero escondido tras la idea de que él o ella sólo es la boca por la que habla la constitución, cerrando con ello todo debate posible. Nada sería más acorde con mi manera de enfrentar el Derecho y los ideales del imperio de la ley que una posición garantista posible, pero si la textura del lenguaje constitucional hace muchas veces que no sea posible, es preferible aceptar esta situación abiertamente y no engañarse uno mismo pensando que las soluciones que tienen previstas los preceptos constitucionales están tasadas y son claramente reconocibles. De lo contrario se corre el riesgo, no ya de que nuestras preferencias morales invadan el Derecho, sino de que se disfracen de Derecho y tomen prestado de la Constitución todo su valor normativo y simbólico.

C) Y para terminar, son necesarias algunas acotaciones a la crítica a la llamada «ponderación». Es éste un tema en el que, como en los anteriores, no me siento lejano de FERRAJOLI; incluso diría que voy más allá que él. Debo confesarlo sinceramente, aun a riesgo de no poder pasar por ser un jurista puesto al día: entiendo poco qué es eso de la ponderación, y lo que entiendo no acaba de convencerme. Sin embargo tampoco veo muy claro si puede aceptarse la posición de FERRAJOLI. 
La doble distinción que hace FERRAJOLI entre ponderación legislativa y ponderación judicial por un lado, y principios directivos y principios regulativos por otro, es pertinente. La ponderación legislativa entraría en funcionamiento respecto de la realización de los estados de cosas que se contienen como objetivos o fines en los principios directivos. A primera vista, si el principio constitucional establece como deseable un estado de cosas al que hay que tender, el legislador, con una gran libertad, ha de establecer medidas que se enderecen a ese fin, porque si esos principios son lo que ALEXY llama «mandatos de optimización», son mandatos sobre todo al legislador. El problema surge cuando la actuación del legislador en busca de esa optimización invade o puede invadir situaciones o estatus protegidos por otros principios o normas; entonces el legislador tiene que ponderar si su intervención, sus medidas son «proporcionales» al caso. Si se somete al juez constitucional alguna de esas medidas se dice que el juez debe iniciar un programa de argumentación más bien complejo para determinar si se ha respetado ese principio de proporcionalidad. Eso, como es sabido, incluye establecer si las medidas son idóneas, si son necesarias, si pueden tomarse otras que invadan menos otros estatus, y todas esas cosas que están ya casi formalizadas y, en algunos casos, pretendidamente cuantificadas. FERRAJOLI acepta esto hasta un cierto grado, pero se niega a admitir que el legislador pueda elegir entre dos principios constitucionales, pues ello le daría la estatura de legislador constituyente, y tampoco acepta de buen grado esa idea de que la garantía de algún derecho pueda comportar el sacrificio de otro, pues, afirma, las relaciones entre derechos son sobre todo de «sinergia», es decir, que la realización de unos potencia la realización de otros. En cuanto a lo primero, mi posición es que, si no totalmente, al menos parcialmente el legislador necesariamente elige qué principios desarrollar, y ello puede significar que algunos no sean realizados plenamente o sean directamente ignorados. En cuanto a lo segundo, creo que se trata simplemente de una afirmación sobre hechos contingentes que admite todo tipo de excepciones. Mi posición es otra. Dejando a un lado la peliaguda cuestión de que muchas veces esa actividad «ponderativa» puede suponer la interferencia de la justicia constitucional en la elaboración democrática de las políticas públicas, el problema de la ponderación del legislador, y del correlativo pronunciamiento del juez sobre si tal ponderación es proporcional o no, es que, el mundo de las directrices o de lo que ALEXY denomina «mandatos de optimización» sitúa la argumentación en el plano de las relaciones medio-fin, en un plano teleológi$\mathrm{co}^{9}$, y entra así en un universo de conjeturas sobre los efectos y las causas, los medios y su efectividad, las medidas y pesos que han de ser utilizados para ello, etc., que es ilusorio que pueda ser disciplinado y racionalizado adecuadamente, y más dudoso aún que pueda ser realizado por un juez. Eso de la «optimización» es sencillo de decir, pero complicado de hacer y de juzgar. No sólo es difícil concebir que un juez (o cualquiera) pueda llegar a un aserto fundado sobre qué efectos van a tener qué medios cuando se está hablando de políticas públicas que afectan a sociedades muy complejas e informadas, es que la pretensión de medir cosas tales como la «intensidad de la intervención» (ALEXY) o el «peso» de los principios en conflicto me parece ilusoria, e inevitablemente dependiente de enunciados éticos subyacentes. Las consideraciones

9 HaBERMAS advirtió esto cuando se enfrentó a la jurisprudencia constitucional alemana inspirada en una teoría de bienes o valores, tan influyente entre nosotros (cfr. J. HABERMAS, Facticidad y validez, Madrid, Trotta, 1998,326 y ss.). 
que hace FERRAJOLI sobre que la llamada ahora ponderación no es sino la apreciación de las circunstancias de hecho previstas en las normas (y no la ponderación de las normas o los principios mismos) como actividad común en las decisiones judiciales, o sobre los problemas que suscitan los márgenes de ambigüedad e indeterminación del lenguaje legal (y mucho más todavía la llamada de atención que hace a una mejora en la calidad y la precisión de las leyes) me parecen muy atendibles, pero me parecen, por un lado, argumentos insuficientes frente al problema que plantean los «principialistas», y por otro lado, débiles frente a la supuesta solución racional que pretende ser la ponderación.

Y eso por lo que respecta a los principios que llama «directivos». En cuanto a los principios «regulativos», o principios en sentido estricto, la llamada ponderación no tiene, en mi opinión, papel alguno que jugar. Es aquí donde yo voy más allá que FERRAJOLI, quien - creo, aunque no soy capaz de identificar esta tesis con un texto concreto de su obra - se niega a aceptar que pueda haber conflictos normativos constitucionales que no puedan ser resueltos limpiamente [es decir, mediante un enunciado «verdadero» (veritas non auctoritas facit iudicium)] por el juez. Si esto es así (cosa que, naturalmente, someto a su juicio), no puedo estar de acuerdo con él. Para terminar y en trazos muy gruesos, trataré de decir por qué.

Los enunciados constitucionales que confieren abstractamente a todos derechos fundamentales pueden a mi juicio ser vistos, en efecto, no como reglas, sino como principios, y ello aun si se mantiene la visión de esa distinción como una mera cuestión de grado y nada más. Esto puede ser así en virtud de dos rasgos: en primer lugar, por su grado de abstracción, generalidad y vaguedad o indeterminación, que determina que el supuesto de hecho que habría de presidir su aplicación a un caso sea por lo común extremadamente impreciso y abierto; en segundo lugar, por su más amplio grado de vocación justificatoria. Lo que esto quiere decir es sencillo de entender: los principios, con toda la abstracción de su fórmula, pueden ser entendidos como la justificación subyacente a amplios conjuntos de normas o reglas, tanto generales como particulares, de forma tal que cada principio rige o puede regir para un ámbito muy amplio de supuestos posibles, de «casos». Alguna vez he afirmado que dado lo abierto y abstracto de su fórmula, simplemente no entran en conflicto unos con otros, que los conflictos entre principios son sólo aparentes: son las normas que ellos justifican las que eventualmente pueden entrar en conflicto, pero los principios no. Los supuestos concretos que van definiendo los casos son los que van operando el descenso gradual desde el principio abstracto hacia la regla más o menos concreta. Y es la regla concreta la que puede entrar en conflicto con otra regla de parecido nivel de concreción que esté justificada por, o descienda de, otro principio diferente. Y cuando se da el caso de que esto ocurre, no vale, en mi opinión, ponderar ni sopesar: es inevitable tener que elegir entre ambas reglas en virtud de criterios que no están explicitados (o que, simplemente, no están) en el ordenamiento jurídico. Esos criterios, por muchas vueltas que le demos, son criterios morales a los que se adhiere el juez para mostrar su preferencia por una solución u otra. Y aquí, desde luego, tendría que serle exigida una argumentación pública de esa naturaleza. Si, como FERRAJOLI mantiene, en ese terreno de la ética estamos en el mundo de lo incognoscible e inefable, las decisiones judiciales para esos casos serán necesariamente arbitrarias, y el juez se transformará así en un poder imposi- 
ble de someter a pautas normativas racionales si aceptamos, como él lo hace, que las argumentaciones morales no son susceptibles de raciocinio o conocimiento. Lo paradójico es que esto, el sometimiento del juez a pautas que estén por encima de él, es una de las inspiraciones básicas que seguramente han llevado a FERRAJOLI a levantar toda su imponente teoría. 